\title{
Role of tides in Arctic ocean/ice climate
}

\author{
Greg Holloway ${ }^{1}$ and Andrey Proshutinsky ${ }^{2}$ \\ Received 13 April 2006; revised 7 November 2006; accepted 14 December 2006; published 28 March 2007.
}

[1] A three-dimensional coupled ocean/ice model, intended for long-term Arctic climate studies, is extended to include tidal effects. From saved output of an Arctic tides model, we introduce parameterizations for (1) enhanced ocean mixing associated with tides and (2) the role of tides fracturing and mobilizing sea ice. Results show tides enhancing loss of heat from Atlantic waters. The impact of tides on sea ice is more subtle as thinning due to enhanced ocean heat flux competes with net ice growth during rapid openings and closings of tidal leads. Present model results are compared with an ensemble of nine models under the Arctic Ocean Model Intercomparison Project (AOMIP). Among results from AOMIP is a tendency for models to accumulate excessive Arctic Ocean heat throughout the intercomparison period 1950 to 2000 which is contrary to observations. Tidally induced ventilation of ocean heat reduces this discrepancy.

Citation: Holloway, G., and A. Proshutinsky (2007), Role of tides in Arctic ocean/ice climate, J. Geophys. Res., 112, C04S06, doi:10.1029/2006JC003643.

\section{Introduction}

\subsection{Arctic Ocean/Ice Modeling and AOMIP}

[2] Global climate modeling shows the Arctic to be one of the most sensitive regions to climate change. A concern is that many climate models do not reproduce well states of the Arctic ocean/sea ice/atmosphere system. For examples, the extent and thickness distribution of sea ice may be poorly estimated, and the vertical structure in the Arctic Ocean interior may misrepresent the subsurface warm saline Atlantic Layer [e.g., Battisti et al., 1997; Briegleb and Bromwich, 1998; Weatherly et al., 2000; Bitz et al., 2002; Moritz et al., 2002; DeWeaver and Bitz, 2006; Holland et al., 2006; Knutson et al., 2006; Parkinson et al., 2006].

[3] To help identify sources of, and possible remedies for, model deficiencies, an Arctic Ocean Model Intercomparison Project (AOMIP) has brought together an international consortium of 15 (at present) Arctic ocean-ice modeling groups with model domains ranging from global to Arctic regional scales and resolutions ranging from fine $(9 \mathrm{~km})$ to coarse $(111 \mathrm{~km})$. Forced nearly identically from NCAR/ NCEP atmospheric reanalyses over 1948 through 2005, with common riverine and precipitation forcing, and with many internal parameters set identically, results to date exhibit great disparity in nearly every analyzed quantity [Proshutinsky et al., 2001, 2005; Steele et al., 2001; Karcher et al., 2002, 2007; Koeberle et al., 2002; Kauker et al., 2002; Steiner et al., 2004; Uotilla et al., 2006; Johnson et al., 2007; Holloway et al., 2007; Martin and Gerdes, 2007]. Heat and freshwater balances, sea level, and sea ice thickness and motion, differ significantly from

\footnotetext{
${ }^{1}$ Institute of Ocean Sciences, Sidney, British Columbia, Canada.

${ }^{2}$ Woods Hole Oceanographic Institution, Woods Hole, Massachusetts, USA.

Copyright 2007 by the American Geophysical Union. 0148-0227/07/2006JC003643\$09.00
}

model to model. Circulations of Atlantic Water differ with some models showing clockwise, other models showing counterclockwise, motion.

[4] Disparities among AOMIP model outputs, despite averaging over space and time, clearly show sensitivity to choices of grid resolution, model parameters and forcing. For example, models show differences in total Arctic heat storage, referenced to $0^{\circ} \mathrm{C}$ (Figure 1). Exact definitions and domain of integration are detailed in an accompanying study [Holloway et al., 2007]. This example is chosen for its special relevance later in the present paper. AOMIP studies address the overarching question: How can the representation of high-latitude processes in Arctic ocean/ ice models be improved?

[5] Among processes that have not been represented in modeling studies of Arctic Ocean climate is the role of tides. In what follows, we review observational evidence of roles of tidal forcing in the Arctic. We recall prior efforts at explicit tidal modeling in the Arctic and related studies of effects of tides in high latitude seas. We consider reasons that omission of tides from Arctic climate modeling may be particularly troubling. Then we turn to exploratory effort to represent the effects of tides within a longer term, climate-oriented Arctic ice/ocean model from the AOMIP consortium.

\subsection{Observational Evidence of Tidal Forcing in the Arctic}

[6] Periodic changes and strong ice shear were observed by early northern travelers [Litke, 1844]. Nansen [1898, 1902] reported the spring/neap cycle of ice pressure affecting the Fram as it drifted with ice, and suggested this was a result of ice interaction with the M2 tidal wave propagating from the North Atlantic. The importance of tides in ice covered seas was considered by Sverdrup [1926], Zubov [1945], Murty [1985], Prinsenberg [1988], Bourke and Parsons [1993], Pease et al. [1994, 1995], and others. 


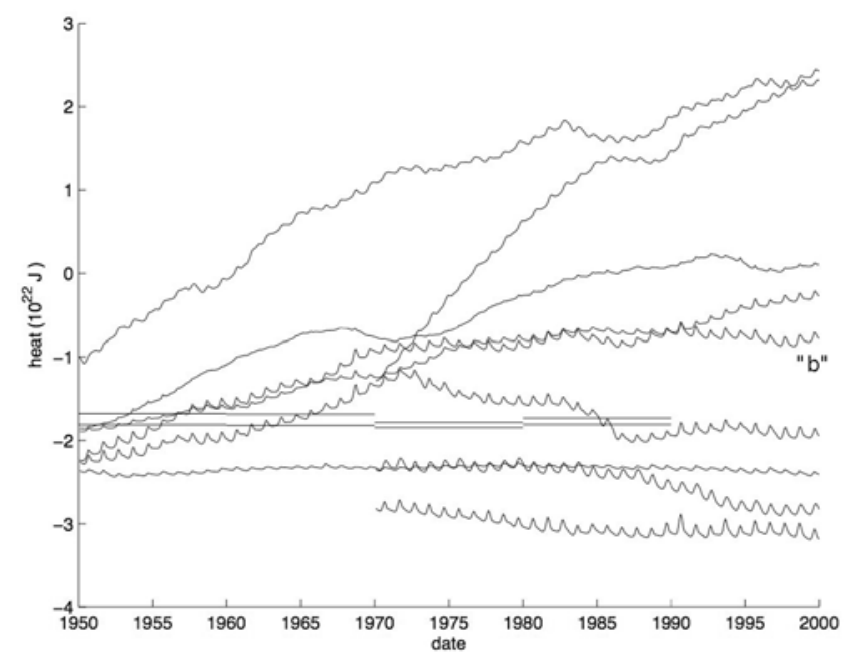

Figure 1. Total oceanic heat referenced to $0^{\circ} \mathrm{C}$, monthly averaged and integrated over the Amerasian and Eurasian basins, is plotted in units of $10^{22} \mathrm{~J}$. Horizontal lines during the 1950s through 1980 s are decadal mean heat from $E W G$ [1997, 1998] summer and winter atlases. Results from the present model are given by the trace marked " $b$ " which will be expanded and discussed further in Figure 9. Other traces are from AOMIP models that are identified and discussed, along with definition of averaging domains, in Holloway et al. [2007].

[7] Tidal effects on sea ice have also been observed in satellite images. Figure 2 illustrates tidal ice drift where elliptically shaped channels in the ice field, formed behind grounded icebergs, reveal their tidal origin. From closely spaced (in time) RADARSAT images, Kwok et al. [2003] observed persistent oscillatory ice motion at mixed inertialtidal frequencies.

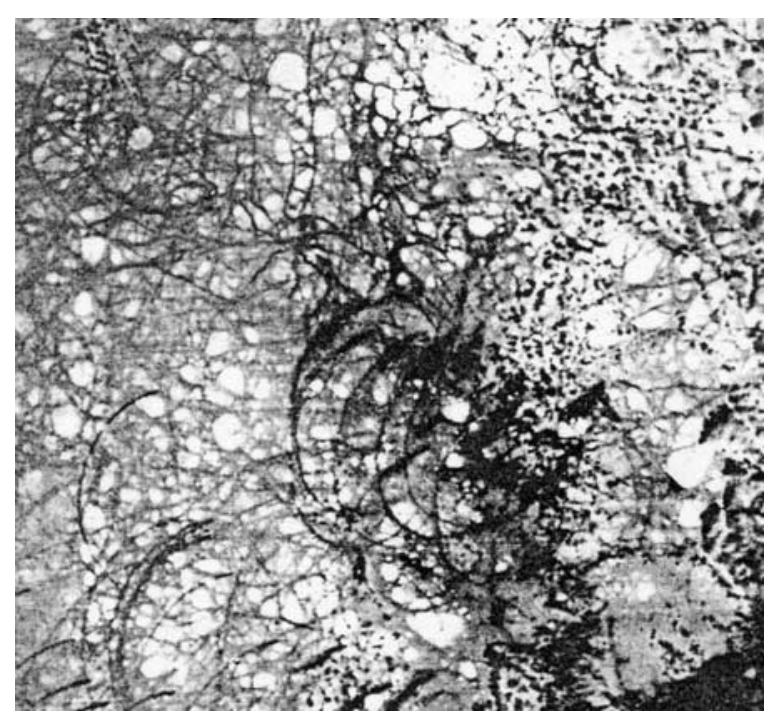

Figure 2. Satellite image of ice cover in the vicinity of Spitsbergen on June 1, 1988, from Dmitriev et al. [1991] with permission from Polar Research. Elliptically shaped leads are formed behind grounded icebergs as sea ice is driven by tidal currents.

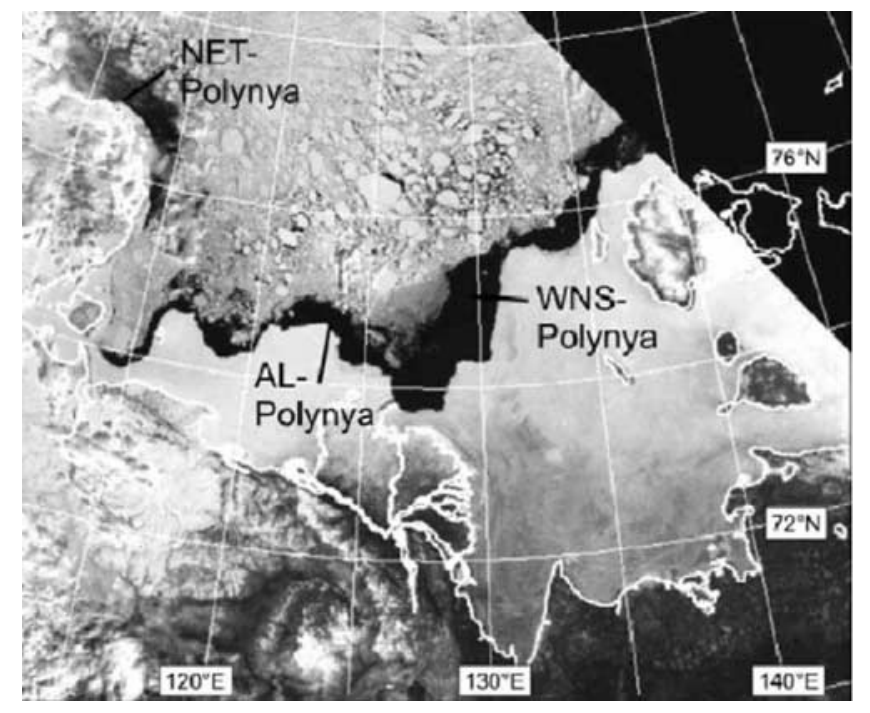

Figure 3. NOAA AVHRR image (visible channel) of the Laptev Sea polynyas (Great Siberian Polynya) on 3 June 1995; adapted for this paper from Bareiss and Gorgen [2005] with permission from Elsevier. The main flaw polynyas as parts of the Great Siberian Polynya are: Northeastern Taimyr Polynya (NET), Anabar-Lena Polynya (AL), West New Siberian Polynya (WNS) and East Severnaya Zemlya Polynya.

[8] Interactions of tides with ice result in a number of phenomena. Along the continental slope of Siberia, the "Great Siberian Polynya" develops in winter (Figure 3). The most favorable conditions for this polynya start with offshore winds that transport the pack ice into the open sea. Atlantic water then upwells along the continental slope and canyons where strong tidal currents cause mixing that transfers heat to the surface resulting in ice thinning and disappearance [Proshutinsky, 1993; Kowalik and Proshutinsky, 1993, 1994, 1995, hereafter KP]. Similar phenomena likely occur over the Yermak Plateau [Padman et al., 1992; Plueddemann, 1992; Padman, 1995], Chukchi Cap, Barrow Canyon, in the Lincoln Sea [Kozo, 1991], and in other Arctic regions with steep bathymetry.

\subsection{Arctic Tidal Modeling Studies}

[9] Detailed reviews of the theories and methods that have been used to investigate tides in the Arctic Ocean have been provided by KP, who studied tides in the Arctic Ocean using numerical simulations based on depth integrated momentum equations, plus additional equations to describe the dynamical interactions of the ice with the ocean. The model grid spacing was $13.89 \mathrm{~km}$. Tidal harmonics derived from satellite data [Cartwright et al., 1991] and observations at coastal stations in the vicinity of open model boundaries were used as boundary conditions. Tidal harmonic constants from more than 300 tide stations, current meter data from 12 locations, and 400 GEOSAT altimetry measurements were used for comparisons with simulated results, showing good agreement.

[10] Simuated tidal parameters were recently improved by Padman and Erofeeva [2004, hereafter PE] using a 5 km grid and a linear-dynamic model and inverse model from Oregon State University Tidal Inversion Software package. 
The new Arctic inverse model assimilates coastal and benthic tide gauges and TOPEX/Poseidon and ERS altimetry. Significant improvement in the accuracy of the simulated tides was reported in the Canadian Straits which were not resolved well in KP. For other regions, some improvements in accuracy were achieved due to tidal data assimilation, but the physics of tidal processes was represented relatively poor by $\mathrm{PE}$ in their 2-D barotropic model with linear dynamics and without ice. PE concluded: "the longterm goal should be to develop dynamics-only models with comparable accuracy, since regions for which no tidal records are available (notably the central deep Arctic basins) will be better modeled by accurate dynamics than by extrapolation of a solution constrained by near-coastal height data. Significant improvements are likely through further increasing model resolution, adding ice-ocean interactions, and increasing the sophistication of dissipation parameterizations."

[11] KP further demonstrated that tide-ice interactions for both tidal and ice drift processes are very significant in the shallow regions and along the continental slope where tides are strongest. Over the deep ocean, their calculations showed that ice does not influence tidal wave propagation and that there is no significant correlation between ice characteristics and amplitudes of tides. Heil and Hibler [2002] criticized this model, reconsidered tide-ice interactions mechanisms, and began developing a barotropic iceocean tidal model with an oceanic boundary layer and imbedded ice [Hibler et al., 2004]. Initial results show that high-frequency (tidal or near-inertial) forcing is important for ice drift and deformations even in the vicinity of North Pole. These oscillations must be associated with windforced excitation of near-inertial ice motion, or possibly baroclinic tides, since barotropic tides in this region are small (PE).

[12] Whereas the aforementioned tidal modeling has been conducted at fine resolution in 2-D, there have been at least two attempts to simulate arctic tides using 3-D models. Polyakov et al. [1995] employed a 3-D, primitive-equation numerical model with a spatial resolution of $55.5 \mathrm{~km}$ that simulated the M2 tide in the Arctic Ocean. This model results showed that tidal mixing can explain important features of the observed spatial distribution of salinity in the Arctic Ocean. Parsons [1995] showed the importance of tides in the formation of vertical and horizontal structure of currents and density fields in the vicinity of the Barents Sea Polar Front using an Arctic Ocean and Nordic Seas version of the Semtner and Chervin [1988] model. Water temperature and salinity fields throughout the Barents Sea were significantly different between the simulations with, and without, tides and the modeled fields were closer to observations when tides were included.

\subsection{Related Studies of Tidal Effects in High-Latitude Seas}

[13] Several studies have considered effects of tides on the larger-scale oceanography and sea-ice distribution for seas surrounding Antarctica and in the Sea of Okhotsk. Here we summarize some of these findings as they pertain to the present focus on the Arctic Ocean.

[14] Robertson et al. [1998] developed a barotropic tide model for the Weddell Sea, and found that tidal currents were sufficient to provide significant drag on the wind- and thermohaline-forced Weddell Gyre. This result is consistent with Parsons [1995], who found that frictional coupling of low-frequency flows with tides modified the mean flow across the Barents Sea. Robertson et al. [1998] also showed that the spatial distribution of currents in the Weddell Sea indicated a potential for influence of tides on the sea-ice cover although no attempt was made to model the ocean-ice coupling.

[15] From ice-mounted buoy observations, Padman and Kottmeier [2000] found that periodic tidal ice divergence increased the lead (open water) area in tidally dominated regions along the Weddell Sea shelf break. Combining measured buoy motion with a kinematic-thermodynamic sea ice model, Eisen and Kottmeier [2000] demonstrated increased winter oceanic heat loss with increased salt flux to the upper ocean due to new ice formation in the leads.

[16] Koentopp et al. [2005] further investigated the effects of tides on the seasonal fluctuations and regional differences of the sea ice cover in the Weddell Sea using a dynamic-thermodynamic sea ice model operating at high temporal and spatial resolution. From two model runs, one with atmospheric forcing only and the other including barotropic tides, they found tidal currents created a highly variable stress at the ice/water interface, leading to straining of the ice cover and to increased upper-ocean mixing with heat flux to the ice base. Comparisons of the two runs demonstrated that tidal currents alter the local and, to lesser extent, basin-wide evolution of sea ice, reducing expansion of the ice cover, speeding up ice retreat, and leading to smaller minimum ice extent. The most significant local differences between the two runs were found in tidally active regions over the continental shelf breaks and at the edges of the ice pack.

[17] Whereas results described above were based on barotropic tides, Robertson [2005] and Padman et al. [2006] demonstrated that inclusion of baroclinic tides can substantially increase the stress divergence applied by the ocean to the sea-ice cover, amplifying the effect of tides on the annual cycle of sea-ice formation and melt and on the upper-ocean thermohaline structure. Baroclinic tides also provide a source of energy for mixing in the midwater column.

[18] As well, Polyakov and Martin [2000] showed from a coupled ice-ocean model that tides are important in the establishment and maintenance of a polynya over Kashevarov Bank in the Sea of Okhotsk. While ice was found to grow in areas around the bank, tidal mixing of oceanic heat to the sea surface resulted in net melting and polynya formation. Nonlinear interactions among large amplitude currents of the basic tidal waves generated a clockwise residual ocean current and ice drift.

\section{Effects of Tides on Arctic Climate}

[19] Observations and modeling show tides clearly present in the Arctic, powerfully expressed in some regions. Influences of tides in high-latitude oceans and sea ice were described above. However, before considering how to include tidal influences into Arctic Ocean climate modeling, we pause to ask why this might be especially important from a climatic perspective. 


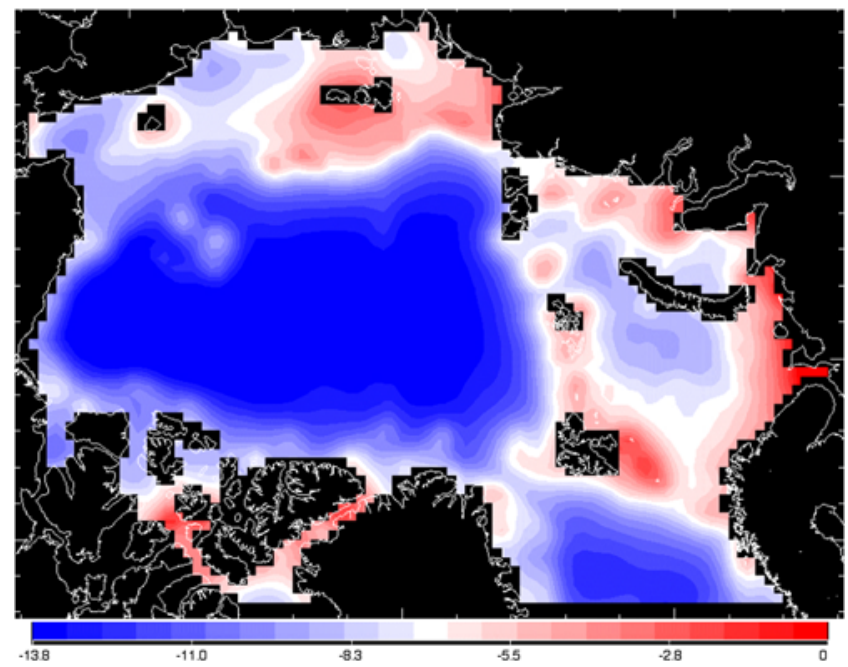

Figure 4. Logarithm of water column averaged tidal energy dissipation rate (scaled to the maximum rate) from the tidal model KP.

[20] A map of modeled, depth-integrated tidal dissipation (Figure 4) shows many orders of magnitude variation in intensity. Other than high dissipation in the southern Barents and White Seas, and in channels of the Canadian Archipelago, bands of high dissipation are found mainly along opening to the Barents Sea, in Fram Strait and along the Laptev and Siberian slopes. This distribution of regions of high dissipation leads to the second part of the answer why tides may be especially important to Arctic climate.

[21] The argument is developed in Figure 5. This is an important extension to usual concepts of global thermohaline overturning, often depicted by "conveyor belt" sketches with a northern overturning terminus occurring near Iceland, while the Arctic is reduced to a mere reservoir that discharges more or less freshwater at sundry times. Instead we suggest that significant components of thermohaline circulation invade the Arctic, accomplishing water mass conversions interior to the Arctic with consequences for global, as well as Arctic, climate. A recent analysis of modeled circulation [Bitz et al., 2006] likewise suggests important thermohaline overturning in the Arctic.

[22] Figure 5 reminds us of another branch of global thermohaline overturning missing from usual "conveyor belt" sketches. This is shallow N Pacific water carrying distant remnants from $\mathrm{N}$ Atlantic/Arctic sinking, here returning to the $\mathrm{N}$ Atlantic through Bering Strait and the Arctic.

[23] The role of tides becomes apparent by comparing Figures 4 and 5. Regions of vigorous dissipation-along opening to the Barents Sea, within the Barents Sea, over the Yermak Plateau, along the Eurasian and Laptev slopes, and along the Siberian slope - are particularly well situated to intercept and ventilate inflowing Atlantic water. Thus tidally induced mixing in the water column has potential to modify Arctic and, perhaps, global climate.

[24] Ventilating Atlantic heat is only part of the story. The Arctic tends to be ice-covered, affecting surface albedo hence summertime absorption of insolation and also providing an insulating "blanket" that isolates the cold wintertime atmosphere from a relatively warm ocean only meters below the frozen surface. Upward mixing of Atlantic heat contributes to a thinning of Arctic sea ice while tidal motion plays a further, not well understood, role by fracturing and mobilizing the ice cover.

[25] Tidal opening of leads releases ocean heat and moisture to the atmosphere while rapidly growing new thin ice (during the freezing season). The tidal forces that open leads also close leads, crushing newly formed ice into thicker ridged ice. Thus tides play competing roles, on one hand bringing up oceanic heat that reduces ice volume while opening summertime leads that receive higher insolation, on the other hand opening and closing wintertime leads that grow and ridge new ice, increasing ice volume. Which role dominates will depend on local circumstances, varying with region and season, while the role of tides fracturing ice cover mobilizes the ice, affecting spatial redistribution.

[26] Our goal is to assess these varying, competing roles of tides as they impact longer term Arctic climate evolution. The effort is exploratory, proceeding simply while anticipating more sophisticated efforts to follow.

\section{Representation of Tides in an Arctic Ice/Ocean Climate Model}

[27] Two modeling approaches are feasible. One can include explicit tidal modeling within a fully 3-D time-

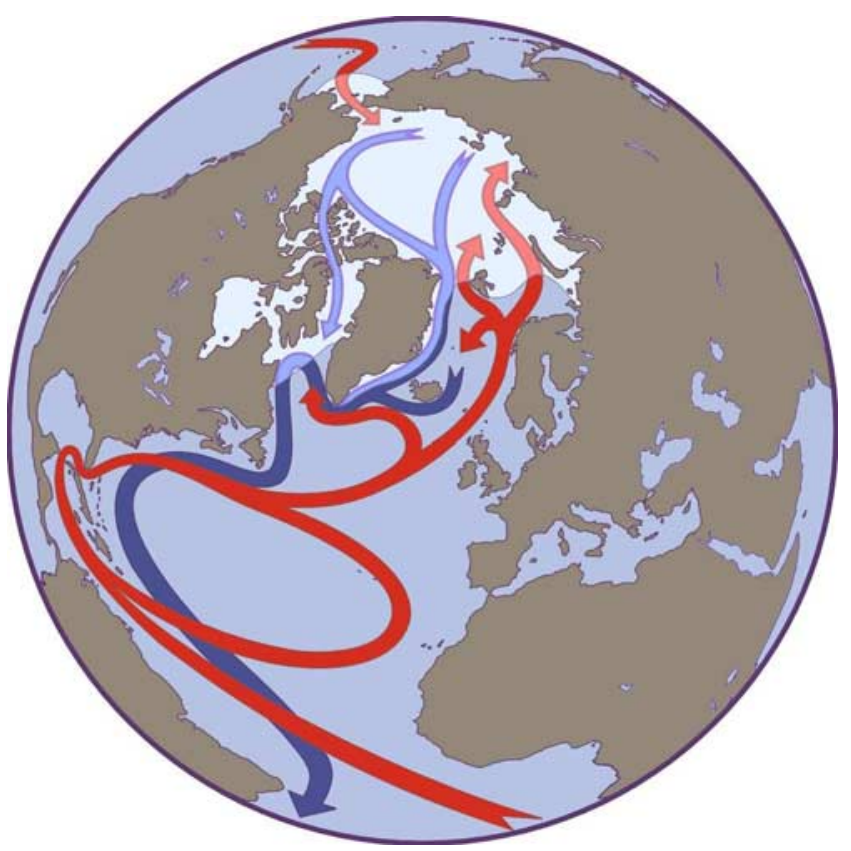

Figure 5. A schematic suggests circulation pathways of the Arctic Ocean and sub-Arctic Atlantic, with warm, saline Atlantic water entering across the Barents Sea and through Fram Strait, then following the Barents slope and around the Laptev Sea [cf. Mauritzen, 1996]. A branch returns along the Lomonosov Ridge while another branch continues along the Siberian slope, and around the Canada Basin. Having given up heat by mixing with overlying colder fresher water, remnant Atlantic water exits the Arctic with the East Greenland Current. Subtropical circulation is after Rahmstorf [1997]. 
stepped general circulation model including all the detailed dynamics and thermodynamics of the ice/ocean system. Examples following this approach were discussed in section 1.4. Since modeling tides requires resolving short space and time scales, there is a computing cost that can limit integrations to modest duration over modest regions. We will explore a different approach which depends more upon conceptualizing tidal influences rather than direct computation. We suggest this as an experiment, exploring phenomena to gain insight with possible utility for longer term, pan-Arctic and global climate integrations.

[28] The ocean's tidal characteristics are determined from an 8-constituent, vertically integrated tidal model coupled with a viscous-plastic sea ice model, evaluated on a $14 \mathrm{~km}$ grid. This is the model of KP with enhancements described at http://www.ims.uaf.edu/tide/index.html. There are concerns using results from such a vertically integrated model when providing parameterizations for a 3-D ocean-ice model, as discussed below. The present study should be seen as an exploration, while advances in Arctic tidal modeling will provide improved representations for future Arctic climate research.

[29] From among the AOMIP suite, we utilize the efficient model 'AIM' (Arctic Ice/ocean Model), enabling multidecadal climate simulations with modest computation. Details of this coarse resolution $(55 \mathrm{~km})$, rigid lid (hence without tides), 29 z-level ocean model with dynamic/thermodynamic sea ice and snow are given in Holloway et al. [2007] where the model results are compared among nine AOMIP models.

[30] Apart from economy, two features of AIM are of particular relevance for the present study: (1) advection of tracers by the second order moment method of Prather [1986], Hofmann and Morales Maqueda [2006], and Morales Maqueda and Holloway [2006]; and (2) horizontal and vertical momentum redistribution follow Neptune after Holloway [2004, and references therein].

[31] The relevances of these features are (1) by providing high quality numerical advection, implicit numerical diffusion and any additional explicit diffusion are made small so that tidally enhanced mixing can be introduced with values motivated from physics; and (2) the model realizes persistent cyclonic circumbasin "rim" currents that are believed to transport Atlantic water through regions of high tidal dissipation. Importantly, these narrow currents overlie the upper slope region, subject to tidally induced ventilation.

[32] From KP we obtain time averaged (over periods of 8 constituents) water-column averaged total energy dissipation, $\varepsilon$, and time averaged magnitude of water-column divergence, $\delta=|\nabla \cdot \mathbf{U}|$. Our goal is to explore the consequences of introducing effects of $\varepsilon$ and $\delta$ into AIM. We proceed as simply as possible, recognizing that more sophisticated parameterizations will follow, with skills that can be measured against the present calculation. By here exploring leading order effects of tides upon the state of Arctic climate, we will assess the merit of further effort concerning tides.

[33] The role of $\varepsilon$ is taken to enhance the vertical mixing coefficient by $\Gamma \varepsilon / \mathrm{N}^{2}$, after Osborn [1980], where $\Gamma$ is a factor estimating the efficiency of conversion of $\varepsilon$ to mixing, and $\mathrm{N}^{2}$ is water-column averaged vertical stability obtained from AIM. We further assume for simplicity that $\varepsilon$ diminishes as $\exp \{-z / \zeta\}$ where $z$ is height above the bottom, $\zeta$ is a height scale, and $\varepsilon$ at the bottom is scaled so that the water-column averaged $\varepsilon$ agrees with KP. The simple exponential is here used consistently with the bottom-frictional barotropic KP while recognizing that more complete (explicit) modeling can involve turbulence closure benthic stress layer and under-ice layer as well as sheardriven turbulence from baroclinic tides. Such information is not available for the present exploration. In experiments (not shown) we did allow also exponential decay downward from under-ice in regions where the ice-cover was nearly closed, hence of reduced mobility with respect to watercolumn tidal motion. As this is an uncertain procedure, which was found not to have large consequence, it is omitted from the present study, retaining only exponential decay up from the bottom.

[34] The role of $\delta$ is introduced into sea ice equations. AIM calculates an area fraction, A, of ice-cover in each cell. Tidal fracturing opens and closes leads (of area fraction 1-A), allowing greater ocean heat loss, more growth of ice, and more mobility for the ice cover. We imitate these influences by reducing the A to an "effective" A at a rate $-\Phi \delta$ $\exp \{-\mathrm{h} / \eta-(1-\mathrm{A}) / \theta \delta\}$ where $\Phi$ is an unknown ice/tide coupling coefficient, $\mathrm{h}$ is the modeled grid-cell averaged ice thickness, and $\eta$ is a thickness scale such that average ice thicker than $\eta$ tends more to resist tidal fracturing. Product $\theta \delta$ is a measure of the fractional surface area gained or lost during a tidal period on account of water column divergence. When open water fraction 1-A exceeds $\theta \delta$, the ice cover is already substantially "open" relative to tidal convergence or divergence, and the effect of tides is reduced. The scheme here proposed differs somewhat from modeling results of Koentopp et al. [2005]. We suppose tidal influences on sea ice are most significant when the ice cover is substantially closed (large A) whereas Koentopp et al. [2005, p. C02014] suggest that a "strong and closed ice cover... mostly suppresses tidal effects". At present this issue is not resolved and we here continue as set out above.

[35] For tests to be reported in section 4 (Results) we must choose parameter values. Appreciating that the simple schemes here proposed will need subsequent refinement or replacement, we consider only plausibility of choices. There are five uncertain parameters: $\Gamma, \zeta, \Phi, \eta$, and $\theta$. Constrained by feasible flux Richardson numbers, Osborn [1980] suggested an upper bound $\Gamma=0.2$ and no lower bound other than $\Gamma>0$. We explore $\Gamma=0.1$ and $\Gamma=0.2$. Exponential decay of $\varepsilon$ upward from the bottom is assumed only from simplicity. Higher order turbulence modeling is suggested, for example, and attention should be given to scattering from barotropic to baroclinic tides, thence to internal wave breaking [Jayne and St. Laurent, 2001; St. Laurent and Garrett, 2002; St. Laurent et al., 2002; Arbic et al., 2004; Simmons et al., 2004a, 2004b]. Baroclinic tides may disperse the associated dissipation over a greater region than is indicated by our present parameterization. For the initial exploration here undertaken, we have simply supposed exponential decay with $\zeta$ ranging from $50 \mathrm{~m}$ to $100 \mathrm{~m}$. Of parameters in the ice equations, $\theta$ is a fraction of the dominant tidal period, for which we take $\theta=3 \mathrm{hr}$, the quarter period of the semidiurnal tide. This leaves $\Phi$ and $\eta$ which, frankly, are poorly constrained in the present simple schemes. High resolution, high frequency ice dynamics are subjects of active research [Hibler et al., 2004] which may 

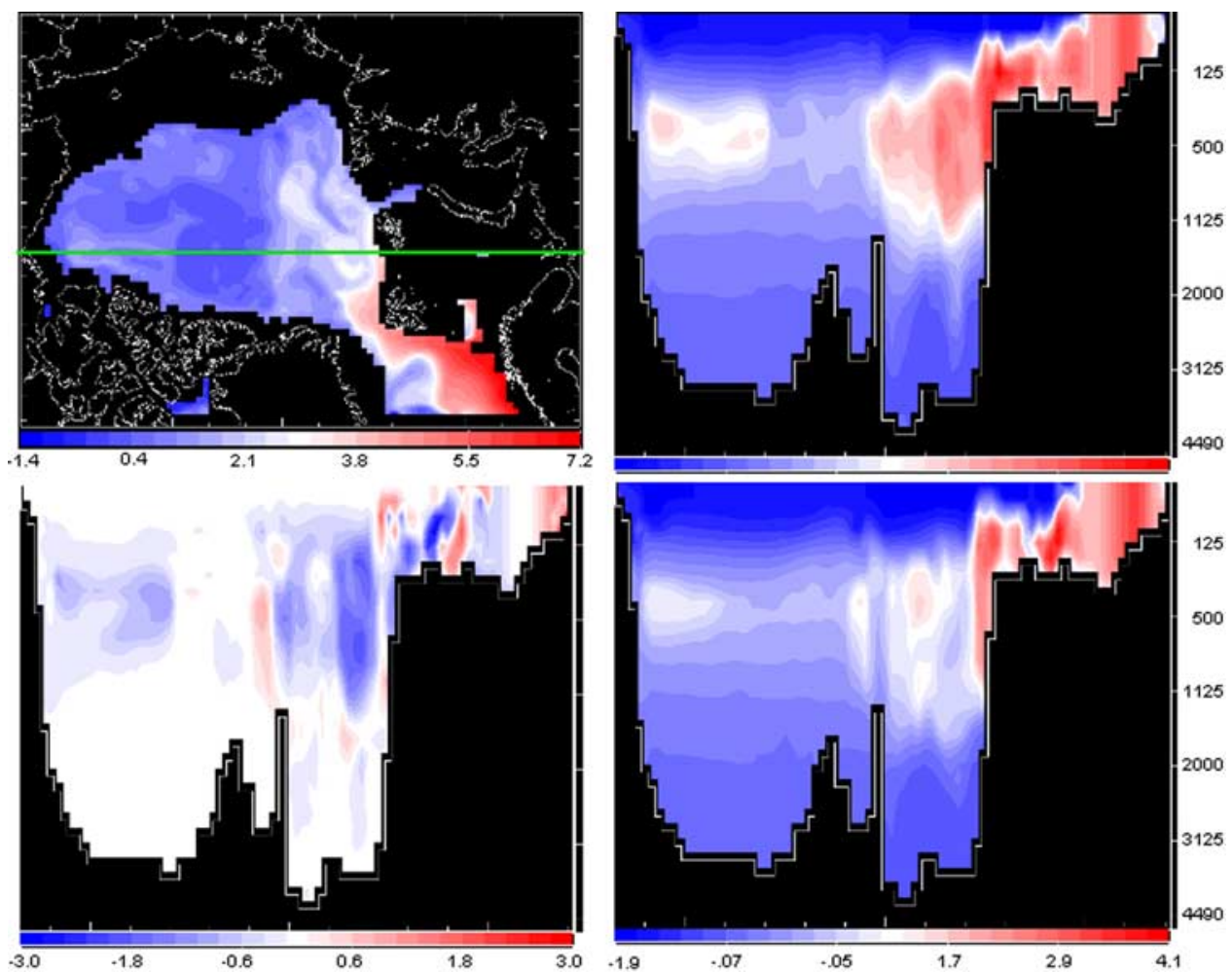

Figure 6. (upper left) Potential temperature $\left({ }^{\circ} \mathrm{C}\right)$ is shown at $320 \mathrm{~m}$ during December 1999 from a case without tides. (upper right) Temperature $\left({ }^{\circ} \mathrm{C}\right)$, without tides, is shown on the vertical section marked by a green bar in the upper left panel. The nonlinear depth scale (meters) is shown on the right. (lower right) Temperature $\left({ }^{\circ} \mathrm{C}\right)$ is shown on the same vertical section, with the same color scale, as upper right but here including effects of tides $(\Gamma=.1, \zeta=100 \mathrm{~m}, \Phi=.1, \eta=1 \mathrm{~m})$. (lower left) The difference of temperature $\left({ }^{\circ} \mathrm{C}\right)$ with tides $(\Gamma=.1, \zeta=100 \mathrm{~m}, \Phi=.1, \eta=1 \mathrm{~m})$ and without tides $(\Gamma=0, \Phi=0)$ is shown on the common vertical section.

come to bear upon some future formulation and parameter choices. Here we only suppose that $\Phi$ is an efficiency of coupling of water column $\delta$ to ice divergence as this impacts effective $\mathrm{A}$ in substantially closed sea ice. Taking $\Phi$ a modest fraction of unity, we explore $\Phi=0.1$ and $\Phi=0.2$. We then take $\eta=1 \mathrm{~m}$ as a simple choice, reflecting present crudeness and inviting future refinement.

\section{Results}

[36] AIM is integrated from 1948 through 2005 according to the AOMIP forcing protocol. Illustrative results are shown for parameter values are listed in the figure captions.

[37] Model results are consistent with observational description. Warm Atlantic water, seen in Figure 6, is carried into the Arctic interior through Fram Strait and across the Barents Sea, flows cyclonically around the Eurasian (Nansen and Amundsen) Basins and also across the Lomonosov Ridge to flow cyclonically around the Makarov and Canada Basins. When tides are included, temperature differences reveal overall heat loss from Atlantic water. The pattern is not simple though, and Figure 7 shows spatial patterns of heat gain and loss at two depth levels.

[38] The influence of tides on long term sea ice budgets and distributions reflects a competition between uncertain terms, reducing ice volume by enhanced upward mixing of ocean heat while increasing ice volume by growth and ridging from opening and closing leads, while allowing greater ventilation of ocean heat. Effects of tides increasing mobility of sea ice and receiving more insolation in tidal leads add further complication, even before we come to the many feedbacks in the overall ice/ocean system. Without tides, the case seen in Figure 6 corresponds to the sea ice thickness distribution shown in Figure 8, as is broadly consistent with descriptions of Arctic sea ice while taking into account overall reduction of sea ice especially during the 1990s.

[39] With the inclusion of tides (as here parameterized), effects on ice thickness are subtle. The upper right panel in Figure 8 shows that regions of thick ice, hence less subject to tidal fracturing, overlying warmer water, are more likely to lose ice thickness due to enhanced oceanic heat flux. Areas of thinner ice, subjected to stronger fracturing and overlying cooler water, realize gains in ice thickness. Redistribution of ice that has been mobilized by tidal fracturing is also a factor, e.g., in passages in the Canadian Archipelago.

[40] Lower panels in Figure 8 show two results, firstly allowing only tidal mixing in the ocean without taking account of sea ice fracturing, then secondly taking into account the combined parameterizations for ocean mixing and for sea ice fracturing. In the first case with only tidal mixing in the ocean, regions of thinning predominate, resulting in overall thinning on average by $4.5 \mathrm{~cm}$ whereas the previous case (upper right: $\Gamma=.1, \zeta=100 \mathrm{~m}, \Phi=.1$ ) experienced smaller average thinning by $0.6 \mathrm{~cm}$. In the 

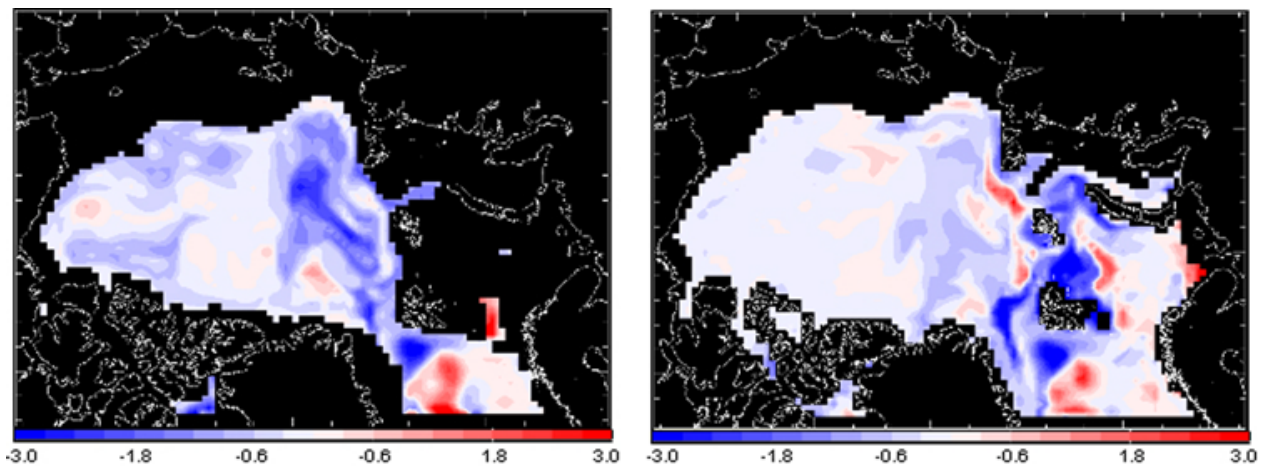

Figure 7. The difference of potential temperature $\left({ }^{\circ} \mathrm{C}\right)$ between the cases with tides and with no tides (namely, Figure 6). (left) At $320 \mathrm{~m}$. (right) At $80 \mathrm{~m}$.

second case with tides in both ocean and ice, but with ice/ tide coupling doubled $(\Phi=.2)$ relative to previous case, regions of thicker and thinner ice contribute an overall small gain in sea ice, thickening on average by $1.9 \mathrm{~cm}$.

[41] Finally we consider the influence of tides on overall heat budgets. Cryospheric and liquid freshwater budgets were considered also, but influences of tides were small (in terms of overall Arctic budgets) and are not shown. For heat, the influence of tides is larger (subject to parameterizations here employed), as seen in Figure 9. The role of tides limiting buildup of Arctic heat is apparent from curves "a", "b", "c". This is important when compared with the ensemble mean of AOMIP cases (which included present case "b" with weak tidal effects as the IOS member in AOMIP). A warming trend throughout $1950-2000$ as expressed by most AOMIP models (but note the dispersion among models in Figure 1) is contrary to EWG atlas results during 1950-1990. This may be of concern when Arctic models are used to help interpret possible Arctic warming during the 1990s and beyond 2000 for which pan-Arctic data are not so available.

\section{Summary and Outlook}

[42] Our goal is exploratory, as the simplicity of the parameterizations in section 3 attests. A first question is,
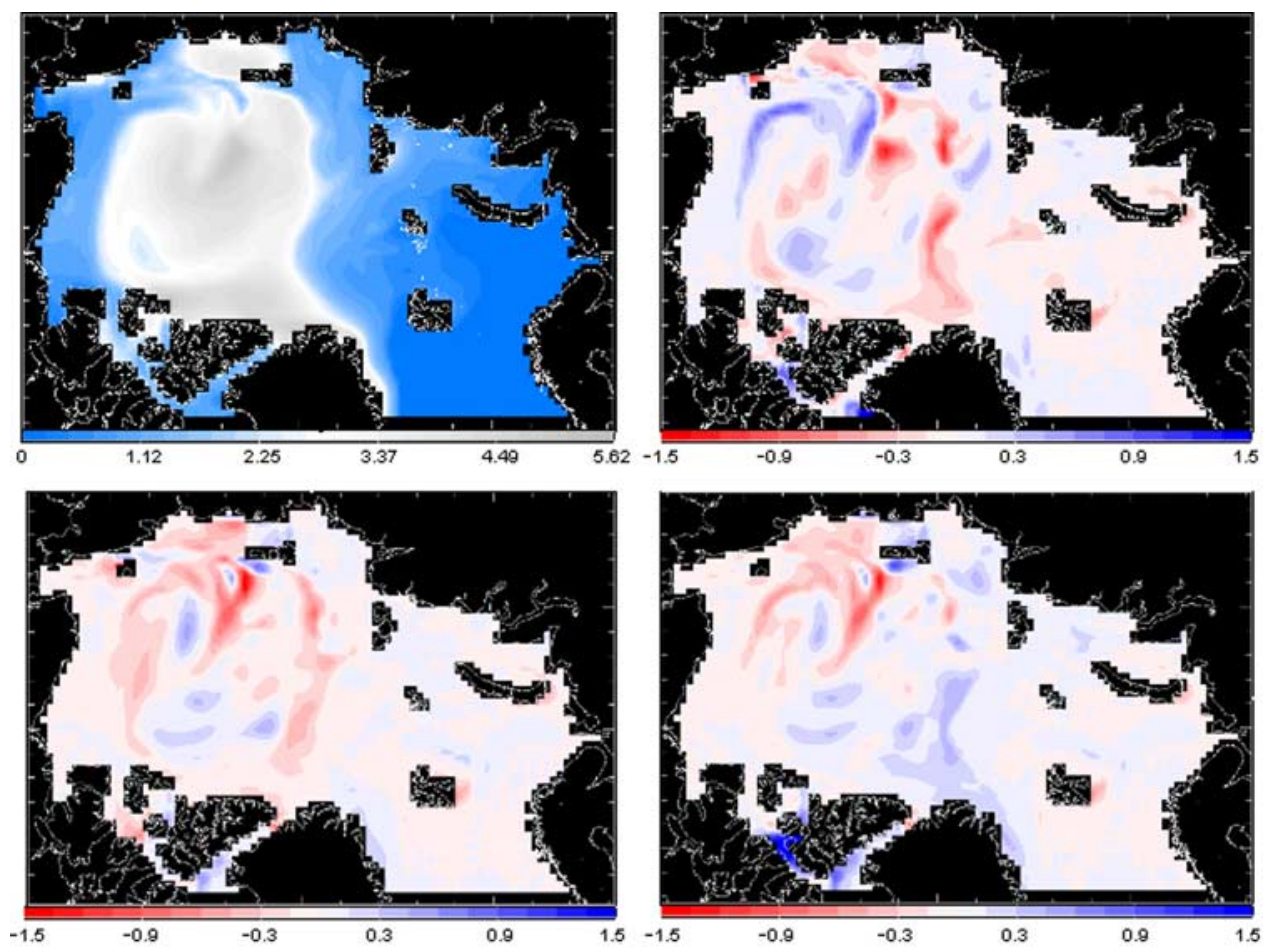

Figure 8. (upper left) Mean ice thickness (meters) during December 1999 from the case without tides. (upper right) The difference of ice thickness (meters) with tides $(\Gamma=.1, \zeta=100 \mathrm{~m}, \Phi=.1, \eta=1 \mathrm{~m})$ and without tides $(\Gamma=0, \Phi=0)$. (lower left) The difference of ice thickness (meters) between a case with tidal mixing only in the ocean $(\Phi=0$, with $\Gamma=.1, \zeta=100 \mathrm{~m}, \eta=1 \mathrm{~m})$ and the case without tides. (lower right) The difference of ice thickness (meters) with stronger ice-tidal parameter $\Phi=0.2$ (with $\Gamma=.1, \zeta=100 \mathrm{~m}$, $\eta=1 \mathrm{~m}$ ) from the case without tides shows overall increased ice compared with the lower left panel $(\Phi=0)$ or with the upper right panel $(\Phi=0.1)$. 


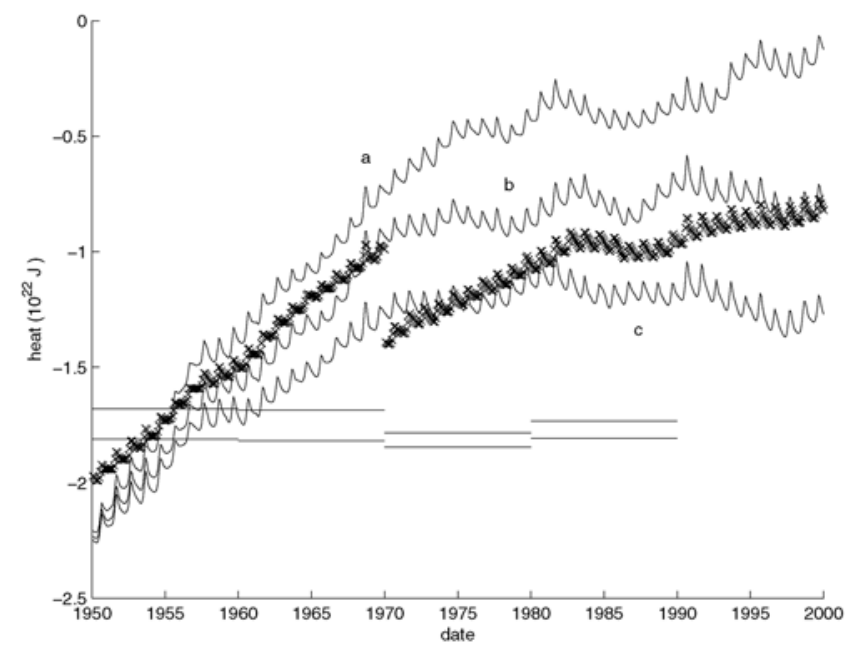

Figure 9. Total oceanic heat referenced to $0^{\circ} \mathrm{C}$, monthly averaged and integrated over the Amerasian and Eurasian basins, is plotted in units of $10^{22} \mathrm{~J}$ for three cases: "a": no tidal influence; "b": weak tidal influence with $\Gamma=.1, \zeta=$ $50 \mathrm{~m}, \Phi=.1$; "c" ": modest tidal influence with $\Gamma=.1, \zeta=$ $100 \mathrm{~m}, \Phi=.1$. Horizontal bars are from EWG decadal mean observations. Crosses mark an ensemble mean of 6 AOMIP models reporting during 1950-1970 then a mean of 9 AOMIP models during 1970-2000. The EWG results and the individual model traces were shown in Figure 1.

for modest choices of parameters such as $\Gamma=.1, \zeta=100 \mathrm{~m}$, $\Phi=.1, \eta=1 \mathrm{~m}$, if the long term state of the modeled Arctic is significantly modified. We clearly see enhanced ventilation of heat from the Atlantic water. This should be considered in context of Figure 5 suggesting an active role of Arctic Ocean processes in poleward heat transport and overturning circulation.

[43] The overall effect on sea ice budgets is less clear, partly from uncertainty in our simple parameterizations and also from competing physical processes, the balance of which will favor thinning or thickening under differing circumstances in differing places and times. However, although impacts on total ice budgets are small, local impacts can be quite large. Much more thorough investigations of sea ice response, subject to refined parameterizations and/or explicit modeling, are clearly indicated in part as suggested by studies described in section 1.4.

[44] It is valuable to perform the present study based on a model that is used in AOMIP. The underlying model has been evaluated within an international suite of models. Among specific features of the present model important to the present study are (1) quality of numerical advection, allowing mixing to be based on physical processes rather than numerical requirements, and (2) model physics that realizes the circumbasins transport pathways of Atlantic heat within the Arctic. Comparison with the ensemble of AOMIP models' outputs reveals modeled tendency to long term Arctic warming since 1950 which is contrary to observations during 1950 to 1990. Enhanced ventilation due to tides, absent from AOMIP models other than the present model, is suggested as a possible "missing physics" that may help correct an over-warming bias in AOMIP models. Beyond AOMIP there is a broader concern among model projections of global warming, including particular warming in the Arctic. Such projections to date have omitted Arctic tides.

[45] Perhaps the main result from the present paper is to motivate further research aimed at the role of tides in Arctic climate. More sophisticated parameterizations and sensitivity studies will be required before one can have confidence in the simple exploratory results here presented. Present results will be improved upon! Stronger efforts may involve explicit tidal solutions along with higher order ocean turbulence modeling, scattering from barotropic to baroclinic tides, etc. Indeed the tidal model output, here used, was based upon barotropic tide whereas it was remarked in section 1.4 that inclusion of baroclinic tide enhances surface divergence, with direct impact on ocean heat loss and sea ice growth. While a review of prior studies (sections 1.3 and 1.4) was far from exhaustive (see bibliographies in the cited papers), it indicates the range of mechanisms by which tides can influence the thermohaline structure, circulation, and sea-ice cover in high-latitude oceans. Attention to detailed sea ice dynamics/thermodynamics will be essential to understanding the balances of losses and gains of ice volume as well as better understanding the role of ice cover in overall ventilation of ocean heat. There are processes that we have not (here) considered at all. Inertial oscillations, similar to tidal oscillations but not predicted from tidal models, are expected to impact ice over and ocean heat loss in ways much as discussed in section 3. Mechanisms of shelf-basin exchange, affecting Atlantic Layer ventilation, should be dependent in part upon tidal/inertial interactions. Foremost the present paper recognizes the potential role of tides, hitherto absent, in model studies of long term Arctic ice/ocean climate.

[46] Acknowledgments. We gratefully acknowledge helpful discussions with Humfrey Melling and insightful reviewer comments from Laurie Padman and Bruno Tremblay. This research is supported by the National Science Foundation Office of Polar Programs under cooperative agreements OPP-0002239 and OPP-0327664 with the International Arctic Research Center, University of Alaska Fairbanks.

\section{References}

Arbic, B. K., S. T. Garner, R. W. Hallberg, and H. L. Simmons (2004), The accuracy of surface elevations in forward global barotropic and baroclinic tide models, Deep Sea Res., Part II, 51, 3069-3101.

Bareiss, J., and K. Gorgen (2005), Spatial and temporal variability of sea ice in the Laptev Sea: Analyses and review of satellite passive-microwave data and model results, 1979 to 2002, Global Planet. Change, 48, 28-54.

Battisti, D. S., C. M. Bitz, and R. E. Moritz (1997), Do General Circulation Models underestimate the natural variability in the Arctic climate?, J. Clim., 10, 1909-1920.

Bitz, C. M., J. Fyfe, and G. Flato (2002), Sea ice response to wind forcing from AMIP models, J. Clim., 15, 522-536.

Bitz, C. M., P. R. Gent, R. A. Woodgate, M. M. Holland, and R. Lindsay (2006), The influence of sea ice on ocean heat uptake in response to increasing $\mathrm{CO}_{2}$, J. Clim., 19, 2437-2450.

Bourke, R. H., and A. R. Parsons (1993), Ambient noise characteristics of the northwestern Barents Sea, J. Acoust. Soc. Am., 94, 2799-2808.

Briegleb, B. P., and D. H. Bromwich (1998), Polar climate simulation of the NCAR CCM3, J. Clim., 11, 1270-1286.

Cartwright, D. E., R. D. Ray, and B. V. Sanchez (1991), Oceanic tide maps and spherical harmonic coefficients from GEOSAT altimetry, NASA Tech. Memo., 104544, 75 pp.

DeWeaver, E., and C. M. Bitz (2006), Atmospheric circulation and its effect on Arctic sea ice in CCSM3 simulations at medium and high resolution, J. Clim., 19, 2415-2436.

Dmitriev, N. E., A. Y. Proshutinsky, T. B. Loyning, and T. Vinje (1991), Tidal ice dynamics in the area of Svalbard and Frans Josef Land, Polar Res., 9, 193-205. 
Eisen, O., and C. Kottmeier (2000), On the importance of leads in sea ice on the energy balance and ice formation in the Weddell Sea, J. Geophys. Res., 105, 14,045-14,060.

Environmental Working Group (EWG) (1997), Arctic Climatology Project [CD-ROM], edited by L. Timokhov and F. Tanis, Natl. Snow and Ice Data Cent., Boulder, Colo.

Environmental Working Group (EWG) (1998), Arctic Climatology Project [CD-ROM], edited by L. Timokhov and F. Tanis, Natl. Snow and Ice Data Cent., Boulder, Colo.

Heil, P., and W. D. Hibler III (2002), Modeling the high-frequency component of arctic sea ice and deformation, J. Phys. Oceanogr, 32, 30293057 .

Hibler, W. D., III, A. Proshutinsky, P. Heil, H. Simmons, and J. Lovick (2004), Tidal and inertial variability in Arctic sea ice drift and deformation, Eos Trans. $A G U, 85(47)$, Fall Meet. Suppl., Abstract OS41A0476.

Hofmann, M., and M. A. Morales Maqueda (2006), Performance of a second-order moments advection scheme in an Ocean General Circulation Model, J. Geophys. Res., 111, C05006, doi:10.1029/2005JC003279.

Holland, M. M., C. M. Bitz, E. C. Hunke, W. H. Lipscomb, and J. L. Schramm (2006), Influence of the sea ice thickness distribution on polar climate in CCSM3, J. Clim., 19, 2398-2414.

Holloway, G. (2004), From classical to statistical ocean dynamics, Surv. Geophys., 25, 203-219.

Holloway, G., et al. (2007), Water properties and circulation in Arctic Ocean models, J. Geophys. Res., 112, C04S03, doi:10.1029/2006JC003642.

Jayne, S. R., and L. C. St. Laurent (2001), Parameterizing tidal dissipation over rough topography, Geophys. Res. Lett., 28, 811-814.

Johnson, M., S. Gaffigan, E. Hunke, and R. Gerdes (2007), A comparison of Arctic Ocean sea ice concentration among the coordinated AOMIP model experiments, J. Geophys. Res., doi:10.1029/2006JC003690, in press.

Karcher, M., R. Gerdes, F. Kauker, and C. Koeberle (2002), Atlantic Water flow in the Arctic Ocean-Comparing models and observations, Eos Trans. $A G U, 83(19)$, Spring Meet. Suppl., Abstract GC52A-07.

Karcher, M., F. Kauker, R. Gerdes, E. Hunke, and J. Zhang (2007), On the dynamics of Atlantic Water circulation in the Arctic Ocean, J. Geophys. Res., doi:10.1029/2006JC003630, in press.

Kauker, F., R. Gerdes, M. Karcher, and C. Koeberle (2002), Variability of the North Atlantic Current and predictability of variability in the Nordic Seas and Arctic Ocean, Eos Trans. $A G U, 83(19)$, Spring Meet. Suppl., Abstract GC51A-12

Knutson, T. R., T. L. Delworth, K. W. Dixon, I. M. Held, J. Lu, V. Ramaswamy, M. D. Schwarzkopf, G. Stenchikov, and R. J. Stouffer (2006), Assessment of twentieth-century regional surface temperature trends using the GFDL CM2 coupled models, J. Clim., 19, 1624-1651.

Koeberle, C., R. Gerdes, M. Karcher, and F. Kauker (2002), Modeled longterm variability of the Arctic fresh water budget, Eos Trans. $A G U$, 83(19), Spring Meet. Suppl., Abstract GC51A-05.

Koentopp, M., O. Eisen, C. Kottmeier, L. Padman, and P. Lemke (2005), Influence of tides on sea ice in the Weddell Sea: Investigations with a high-resolution dynamic-thermodynamic sea ice model, J. Geophys. Res., 110, C02014, doi:10.1029/2004JC002405.

Kowalik, Z., and A. Y. Proshutinsky (1993), Diurnal tides in the Arctic Ocean, J. Geophys. Res., 98(C9), 16,449-16,468.

Kowalik, Z., and A. Y. Proshutinsky (1994), The Arctic Ocean tides, in The Polar Oceans and Their Role in Shaping the Global Environment: Nansen Centennial Volume, Geophys. Monogr. Ser., vol. 85, pp. 137-158, AGU, Washington, D. C.

Kowalik, Z., and A. Y. Proshutinsky (1995), Topographic enhancement of tidal motion in the western Barents Sea, J. Geophys. Res., 100(C2), $2613-2637$

Kozo, T. L. (1991), The hybrid polynya at the northern end of Nares Strait, Geophys. Res. Lett., 18, 2059-2062.

Kwok, R., G. F. Cunningham, and W. D. Hibler III (2003), Subdaily sea ice motion and deformation from RADARSAT observations, Geophys. Res. Lett., 30(23), 2218, doi:10.1029/2003GL018723.

Litke, F. (1844), On Tides in the Great North Sea and Ice-Covered Sea (in Russian), Zapiski Hydrograficheskogo Departamenta Morskogo Ministerstva, chap. 2, pp. 353-376.

Martin, T., and R. Gerdes (2007), Sea ice drift variability in AOMIP models and observations, J. Geophys. Res., doi:10.1029/2006JC003617, in press.

Mauritzen, C. (1996), Production of dense overflow waters feeding the North Atlantic across the Greenland-Scotland Ridge. Part 1: Evidence for a revised circulation scheme, Deep Sea Res., Part I, 43, 769-806.

Morales Maqueda, M. A., and G. Holloway (2006), Second order moment advection scheme applied to Arctic Ocean simulation, Ocean Modell., 14, $197-221$

Moritz, R. E., C. M. Bitz, and E. Steig (2002), Dynamics of recent climate change in the Arctic, Science, 297, 1497-1502.
Murty, T. S. (1985), Modification of hydrographic characteristics, tides, and normal modes by ice cover, Mar. Geod., 9(4), 451-568.

Nansen, F. (1898), Farthest North, 480 pp., George Newnes, London.

Nansen, F. (Ed.) (1902), The Norwegian North Polar Expedition, 18931896: Scientific Results, Pitman, London.

Osborn, T. R. (1980), Estimates of the local rate of vertical diffusion from dissipation measurements, J. Phys. Oceanogr., 10, 83-89.

Padman, L. (1995), Small-scale physical processes in the Arctic Ocean. Arctic oceanography: Marginal ice zones and continental shelves, Coastal Estuarine Stud., 49, 97-129.

Padman, L., and S. Erofeeva (2004), A barotropic inverse tidal model for the Arctic Ocean, Geophys. Res. Lett., 31, L02303, doi:10.1029/ 2003GL019003.

Padman, L., and C. Kottmeier (2000), High-frequency ice motion and divergence in the Weddell Sea, J. Geophys. Res., 105(C2), 3379-3400.

Padman, L., A. J. Plueddemann, R. D. Muench, and R. Pinkel (1992), Diurnal tides near the Yermak Plateau, J. Geophys. Res., 97, 12,63912,652 .

Padman, L., S. Howard, and R. Muench (2006), Internal tide generation along the South Scotia Ridge, Deep Sea Res., Part II, 53, 157-171, doi:10.1016/j.dsr2.2005.07.011.

Parkinson, C. L., K. Y. Vinnikov, and D. J. Cavalieri (2006), Evaluation of the simulation of the annual cycle of Arctic and Antarctic sea ice coverages by 11 major global climate models, J. Geophys. Res., 111, C07012, doi:10.1029/2005JC003408

Parsons, A. R. (1995), On the Barents Sea polar front in summer and interpretations of the associated regional oceanography using an Arctic Ocean general circulation model, Ph.D. thesis, 185 pp., Nav. Postgrad. Sch., Monterey, Calif.

Pease, C. H., P. Turet, R. S. Pritchard, and J. E. Overland (1994), Barents Sea tidal, wind drift, and inertial motion from ARGOS ice buoys during CEAREX, CEAREX report, $134 \mathrm{pp}$.

Pease, C. H., P. Turet, and R. S. Pritchard (1995), Barents Sea tidal and inertial motions from Argos ice buoys during the Coordinated Eastern Arctic Experiment, J. Geophys. Res., 100(C12), 24,705-24,718.

Plueddemann, A. J. (1992), Internal wave observation from the Arctic environmental drifting buoy, J. Geophys. Res., 97(C8), 12,619-12,638. Polyakov, I., and S. Martin (2000), Interaction of the Okhotsk Sea diurnal tides with the Kashevarov Bank polynya, J. Geophys. Res., 105(C2), $3281-3294$

Polyakov, I., E. Dmitriev, and A. Proshutinsky (1995), Modeling of a threedimensional structure of the Arctic Ocean M_2 tide with a high spatial resolution, Cray Channels, 17(2), 36.

Prather, M. J. (1986), Numerical advection by conservation of second-order moments, J. Geophys. Res., 91, 6671-6681.

Prinsenberg, S. J. (1988), Damping and phase advance of the tide in western Hudson Bay by the annual ice cover, J. Phys. Oceanogr., 18, 1744-1751.

Proshutinsky, A. (1993), Variability of Sea Level in the Arctic Ocean (in Russian), 216 pp., Gidrometeoizdat, St. Petersburg.

Proshutinsky, A., et al. (2001), The Arctic Ocean Model Intercomparison Project (AOMIP), Eos Trans. $A G U, 82(51), 637-644$.

Proshutinsky, A., et al. (2005), Arctic Ocean study: Synthesis of model results and observations, Eos Trans. $A G U, 86(40), 368$.

Rahmstorf, S. (1997), Risk of sea-change in the Atlantic, Nature, $388(6645), 825-826$

Robertson, R. (2005), Baroclinic and barotropic tides in the Weddell Sea, Antarct. Sci., 17(3), 461-474.

Robertson, R. A., L. Padman, and G. D. Egbert (1998), Tides in the Weddell Sea, in Ocean, Ice and Atmosphere: Interactions at the Antarctic Continental Margin, Antarct. Res. Ser., vol. 75, edited by S. S. Jacobs and R. F. Weiss, pp. 341-369, AGU, Washington, D. C.

Semtner, A. J., and R. M. Chervin (1988), A simulation of the global ocean circulation with resolved eddies, J. Geophys. Res., 93, 15,502-15,522.

Simmons, H. L., R. W. Hallberg, and B. K. Arbic (2004a), Internal wave generation in a global baroclinic tide model, Deep Sea Res., Part II, 51, 3043-3068.

Simmons, H., L. St. Laurent, S. Jayne, and A. Weaver (2004b), Tidally driven mixing in a numerical model of the ocean general circulation, Ocean Modell., 6, 245-263, doi:10.1016/S1463-5003(03)00011-8.

Steele, M., W. Ermold, G. Holloway, S. Häkkinen, D. M. Holland, M. Karcher, F. Kauker, W. Maslowski, N. Steiner, and J. Zhang (2001), Adrift in the Beaufort Gyre: A model intercomparison, Geophys. Res. Lett., 28, 2935-2938.

Steiner, N., et al. (2004), Comparing modeled streamfunction, heat and freshwater content in the Arctic Ocean, Ocean Modell., 6, 265-284.

St. Laurent, L., and C. Garrett (2002), The role of internal tides in mixing the deep ocean, J. Phys. Oceanogr., 32, 2882-2899.

St. Laurent, L. C., H. L. Simmons, and S. R. Jayne (2002), Estimating tidally driven mixing in the deep ocean, Geophys. Res. Lett., 29(23), 2106, doi:10.1029/2002GL015633. 
Sverdrup, H. U. (1926), Dynamics of tides on the northern Siberian shelf, Geophys. Publ. 4, 5, 76 pp., Oslo, Norway.

Uotilla, P., et al. (2006), An energy-diagnostics intercomparison of coupled ice-ocean arctic models, Ocean Modell., 11, 1-27.

Weatherly, J. W., B. P. Briegleb, and W. Large (2000), Sea ice and polar climate in the NCAR CSM, J. Clim., 11(6), 1472-1486.
Zubov, N. N. (1945), Arctic Ice, 350 pp., Izd. Glavsevmorputi, Moscow.

G. Holloway, Institute of Ocean Sciences, Sidney, BC, Canada V8L 4B2.

A. Proshutinsky, Woods Hole Oceanographic Institution, Woods Hole, MA 02543, USA. 